\title{
CRITICAL SEISMIC COEFFICIENTS OF HOMOGENEOUS EARTH DAMS PREDICTION BY A FELA-ANN APPROACH
}

\author{
Zeroual Abdelatif ${ }^{1}$, Fourar Ali ${ }^{1}$, Djeddou Messaoud ${ }^{2}$ \\ ${ }^{I}$ Faculty of Technology, Hydraulics Department, University of Batna 2, Batna, Algeria \\ ${ }^{2}$ Research Laboratory in Subterranean and Surface Hydraulics (LARHYSS), Faculty of Sciences \\ and Technology, Mohamed Khider University, Biskra, Algeria \\ abdelatifyahia@gmail.com,fourarali05@hotmail.fr,djeddou.messaoud@gmail.com
}

Received: 12 September 2018; Accepted: 1 October 2019

\begin{abstract}
In this research study, a combination of lower and upper bound finite element limit analysis (FELA) and artificial neural network (ANN) has been adopted in order to forecast critical seismic coefficients (kc) of homogeneous earth dams (HED) subjected to pseudo-static seismic loading. To achieve this, the results of $\mathrm{kc}$ obtained by OptumG2 software were used in the development of the ANN and MR models. The ANN models have shown higher prediction performance than the MR models based on the performance indices. The most appropriate architecture was found 8-14-1, as this gave the best kc predict with the minimum statistical measures of error and the high determination coefficient $(>99 \%)$. Consequently, the ANN model can be used to easily and accurately predict kc value of the HED as the best substitute for the conventional methods.
\end{abstract}

MSC 2010: 62-07, 65-04

Keywords: critical seismic coefficient, pseudo-static analysis, finite element limit analysis, artificial neural network, homogeneous earth dams

\section{Introduction}

The critical seismic coefficient of a slope is an important parameter in deciding the seismic safety of an earth dam. In practice, the stability of small earth dams under seismic loading is usually evaluated by applying the conventional pseudo-static method (PSM). The PSM is convenient when critical seismic coefficients $(\mathrm{kc})$ can be estimated. In addition, with these coefficients, permanent deformations of earth dam slopes can be determined using the Newmark simplified procedure [1]. In fact, the kc is calculated as the quotient of the horizontal seismic acceleration, $a_{h}$, to the acceleration of gravity $\left(\mathrm{kc}=a_{h} / g\right.$ ), the critical state corresponding to a factor of safety (FS) equals one [2]. However, this procedure requires much effort and time during iteration [3]. 
In slope stability analysis, the evaluation of FS and $\mathrm{kc}$ is often performed using either conventional approaches (limit equilibrium and limit analysis) or numeric ones (the strength reduction technique). Therefore, different techniques have been proposed to determine the critical seismic coefficient kc (upper bound formulation [4], variational formulation of limiting equilibrium and a strength reduction technique [5], limit equilibrium method and stress acceptability criteria [6],...etc.). Particularly, there is no exacting formulation for selecting the pseudo-static coefficient for designing earth dams with special conditions as anisotropy seepage.

Recently, the finite element limit analysis (FELA), an alternative approach that offers higher-quality results than the conventional methods [7]. So, FELA is a powerful combination of a mathematical and numerical tool with great finite element discretization capabilities for manipulating complex soil, load, and boundary conditions and bound plastic theorems to frame the exact limit load with upper and lower limit solutions [8].

As an alternative practice to the analytical and numerical methods, artificial neural networks (ANNs) have been developed as powerful mathematical and numerical modeling manners that can interconnect complex nonlinear relationships. The ANNs learning capability have used in multivariate complex modeling and have enlarged uses in various fields of geotechnical engineering [9].

The aim of this study is to develop an ANN model in order to achieve quick forecasting of the critical seismic coefficient of homogeneous earth dams (kc) under full reservoir long-term stability condition and anisotropy seepage $\left(K_{h} \neq K_{v}\right)$. The kc assessed by the developed ANN models corresponds well with those obtained by the conventional trial and error approach and, thus, can be applied efficiently for assessing the stability and performance of HED during earthquake shaking.

\section{Numerical model of analysis}

In the present study, the numerical finite element limit analysis software, OptumG2 [10], was used to accurately determine the critical seismic coefficients of homogeneous earth dams (HED). OptumG2 software has been efficiently applied to solve various problems in geotechnical engineering [11].

In the following modeling steps, an HED on an impervious foundation with the geometric parameters shown in Figure 1a is considered. The numerical model of a HED in OptumG2 is shown in Figure 1b. An automatically adaptive mesh refinement with 2,000 elements and 3 adaptivity steps was used in both the upper and lower bound analyses. The mesh was composed of six noded, second-order, plane-strain triangular elements. The boundary condition of this problem is defined as the following: the left boundaries of the problem are allowed to move only in a vertical direction, while the bottom boundary of the model is fixed in both directions. Whereas, an elastoplastic constitutive model following the Mohr-Coulomb failure criterion was assigned to the soil. 
(a)

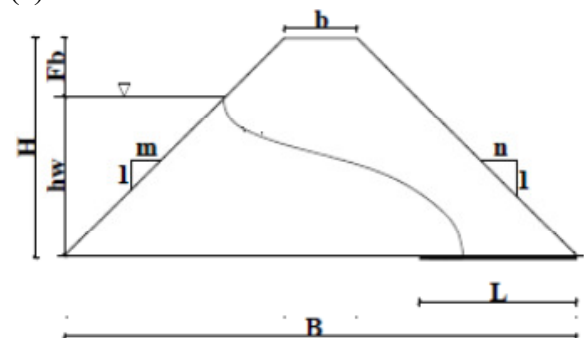

(b)

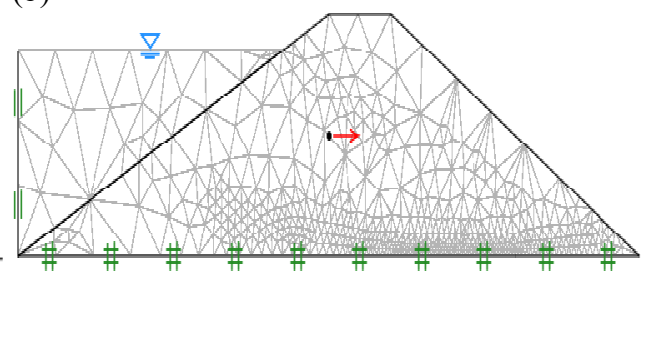

Fig. 1. (a) Geometric parameters of HED with horizontal drain on impervious foundation $(\mathrm{m} / \mathrm{n}$ - Upstream/downstream slope of dam; Fb - Free broad; $\mathrm{b}$ - top width of the dam; hw - Water depth in upstream of the dam); (b) adaptive mesh using OptumG2 software

a)

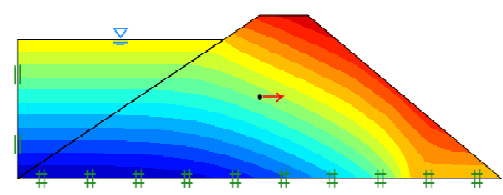

b)

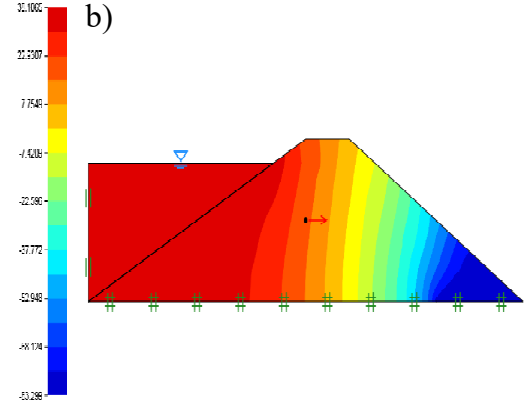

Fig. 2. Sample of results of pseudostatic analysis using OptumG2 software: a) pore pressure $[\mathrm{kPa}], \mathrm{b})$ head water $[\mathrm{m}]$

\section{Research methodology}

The methodology proposed in this study to develop the ANN models contains the following steps:

1. Construction tow representative databases D1 and D2 using the OptumG2 (2017) software. The input variables of the first database contains the different parameters influencing the kc of the HED values: Base width of the dam (B), Height of the dam $(\mathrm{H})$, length of horizontal toe drain (L), unit weight of dam soil $(\gamma)$, effective cohesion $\left(c^{\prime}\right)$, effective friction angle $\left(\varphi^{\prime}\right)$, horizontal permeability $\left(\mathrm{K}_{\mathrm{h}}\right)$, and vertical permeability $\left(\mathrm{K}_{\mathrm{v}}\right)$, while the second database (compacted) present the input data in a dimensionless manner $\left(\gamma / \mathrm{H}_{\mathrm{c}}, \mathrm{K}_{\mathrm{v}} / \mathrm{K}_{\mathrm{h}}, \tan \varphi, \mathrm{L} / \mathrm{B}\right)$.

2. Developing the direct relationships between the selected sets of input variables and the obtained output variables using either Multiple Regression (MR and MR2) and feed forward back-propagation neural network method (BPNN1, BPNN2).

3. Exploitation of the developed ANN models: sensitivity analysis (BPNN1), mathematical equation (BPNN2).

4. Accuracy of the developed ANN models is compared with the existing methods for estimation of kc for some new cases with input values that do not exist in the database constructed in step (1) above. 


\section{Models development}

The detail of development of MR and ANN models for prediction of kc of HED has been discussed hereunder.

\subsection{Artificial neural network models}

ANN can be defined as structures consisting of mathematical processing element famed as neurons, which performs parallel calculations for data processing [12]. The feed forward back-propagation (FB) is often the most common model of neural networks used in geotechnical applications $[13,14]$. In this model, the neuron of the network receives input signals, trains them and sends an output signal. The connection between neurons is represented by a number called weights (w).

\subsubsection{Database and normalization}

The kc evaluation of HED with horizontal drain by FELA in the case of the full reservoir under pseudostatic loading needs to identify a number of parameters. These parameters can be classified into three groups: first, geometric parameters $(B, H, L)$, secondly, geotechnical parameters $\left(\gamma, c^{\prime}, \varphi^{\prime}\right)$ and third one seepage parameters $\left(\mathrm{K}_{\mathrm{h}}, \mathrm{K}_{\mathrm{v}}\right)$.

A dataset of 306 different cases of above eight independent variables as inputs and one dependent variable $\mathrm{kc}$ as an output was built through OptumG2 FELA software and was then used to produce artificial neural network (ANN). Hence, kc is the mean value of the upper bound and lower bound critical seismic coefficient.

Table 1 presents the summary statistics for each variable of the critical seismic coefficient dataset.

Table 1. Summary statistics of the critical seismic coefficient database

\begin{tabular}{|c|c|c|c|c|}
\hline Parameters & Max & Min. & Mean & St.dv. \\
\hline $\mathrm{B}[\mathrm{m}]$ & 142 & 50 & 86.23 & 27.77 \\
\hline $\mathrm{L}[\mathrm{m}]$ & 40 & 0 & 17.57 & 11.82 \\
\hline $\mathrm{H}[\mathrm{m}]$ & 20 & 10 & 14,98 & 4.14 \\
\hline$\gamma\left[\mathrm{kN} / \mathrm{m}^{3}\right]$ & 21 & 15 & 17.23 & 1.99 \\
\hline $\mathrm{c}[\mathrm{kPa}]$ & 50 & 5 & 22.66 & 16.21 \\
\hline$\left.\varphi{ }^{\circ}\right]$ & 50 & 10 & 29.90 & 10.55 \\
\hline $\mathrm{K}_{\mathrm{h}}[\mathrm{m} /$ day $]$ & 0.1 & 0.001 & 0.06 & 0.05 \\
\hline $\mathrm{K}_{\mathrm{v}}[\mathrm{m} / \mathrm{day}]$ & 0.1 & $\mathrm{E}-5$ & 0.04 & 0.04 \\
\hline$\gamma / \mathrm{H}_{\mathrm{c}}$ & 0.38 & 0.02 & 0.12 & 0.12 \\
\hline $\mathrm{K}_{\mathrm{v}} / \mathrm{K}_{\mathrm{h}}$ & 1 & 0.01 & 0.40 & 0.40 \\
\hline $\tan \varphi$ & 1.19 & 0.18 & 0.60 & 0.25 \\
\hline $\mathrm{L} / \mathrm{B}$ & 0.41 & 0 & 0.21 & 0.13 \\
\hline $\mathrm{kc}$ & 0.701 & 0 & 0.25 & 0.16 \\
\hline
\end{tabular}


For FBNN1, before applying the training, the input and output values should be normalized, since most training algorithms are sensitive to the scale of the data. In the present study, the dataset has been scaled to make them bounded into the range $[-1,1]$ using the min-max normalization formula as follows:

$$
X_{\text {normalized }}=\frac{2\left(X_{i}-X_{i, \min }\right)}{\left(X_{i, \max }-X_{i, \min }\right)}-1 \quad(i=1,2, \ldots \ldots \ldots \ldots, N)
$$

where $X_{\text {normalized }}$ and $X_{i}$ represent normalised and actual value respectively. $X_{i, \min }$ and $X_{i, \max }$ represent the minimum and maximum values of the attribute $X_{i}$.

In this study, ANN's modeling has been developed by the use of Matlab software. So, for a better form of the elements that frame the ANN architecture with its developments, our selection of modeling sets were made as follows:

- A random dataset has been distributed into three sets, which are: training set, testing set, and validation set. So, in order to study the training process, a $70 \%$ $(214 / 306)$ of data was used, while the remaining (30\%) was used equally for the testing and validation steps $(46 / 311 ; 46 / 311)$.

- The linear purelin transfer function for the output neuron was selected since it is fitting for continuous-valued targets [15].

- The trial-and-error technique based on the statistical measures was used to determine the optimum neurons in the hidden layer to optimize the ANN architecture.

The principal settings of ANN used in this study are mentioned in Table 2.

Table 2. Settings of ANN used in this study

\begin{tabular}{|c|c|c|}
\hline Setting & ANN1 & ANN2 \\
\hline Topology of the network & \multicolumn{2}{|c|}{ Feed forward } \\
\hline Learning paradigm & \multicolumn{2}{|c|}{ Back propagation } \\
\hline Training algorithm & \multicolumn{2}{|c|}{ Levenberg-Marquardt } \\
\hline Number of hidden layers & \multicolumn{2}{|c|}{$1,1]$} \\
\hline Normalization & hyperbolic tangent sigmoid (tansig) & Log sigmoid (logsig) \\
\hline Activation function & \multicolumn{2}{|c|}{$\mathrm{R}^{2}$, RMSE, MAE } \\
\hline Performance evaluation & $8-\mathrm{j}-1 / \mathrm{j}=4, \ldots, 18$. & $3-\mathrm{j}-1 / \mathrm{j}=2, \ldots, 9$. \\
\hline Network typology & \multicolumn{2}{|c|}{} \\
\hline
\end{tabular}

\subsubsection{Performance evaluation}

In order to quantify the agreement between computed and predicted values of the critical seismic coefficient of HED, we used three statistical measures: root mean-square error (RMSE), mean absolute error (MAE), coefficient of determination $\left(\mathrm{R}^{2}\right)$. These statistical performance evaluation criteria are identified as follows: 


$$
\begin{gathered}
R^{2}=1-\frac{\sum_{i=1}^{N}\left(P_{i}-C_{i}\right)^{2}}{\sum_{i=1}^{N}\left(C_{i}-\bar{C}\right)^{2}} \\
R M S E=\sqrt{\frac{\sum_{i=1}^{N}\left(P_{i}-C_{i}\right)^{2}}{N}} \\
M A E=\frac{1}{N} \sum_{i=1}^{N}\left|P_{i}-C_{i}\right|
\end{gathered}
$$

where: $P_{i}$ - predicted value; $C_{i}$ - computed value; $\mathrm{N}$ - number of observations; $C_{\max }$ - maximum computed value; $C_{\min }$ - minimum computed value; and $\bar{C}$ - averaged computed value.

The methodology practiced to estimate the performance of ANN architecture includes obtaining the minimum statistical measures of error between computed and predicted values. Therefore, the best ANN model was selected on the basis of the lowest (RMSE, MAE) and highest $\mathrm{R}^{2}$ values.

\subsection{Multiple regression (MR) models}

The multiple regression (MR) is a statistical technique that examines causeeffect relations between dependent and independent variables [16]. The data used while developing the ANN models were used in the development of the MR models. The two MR models revealed the following correlations:

$\mathrm{kc}=-0.293+0.002 B+0.004 L-0.014 H+0.008 c+0.008 \varphi+$ $0.007 \gamma-0.306 K_{h}+0.169 K_{v}$

$$
\mathrm{kc}=0.083-0.931 \frac{\gamma}{H_{c}}-0.026 \frac{K_{v}}{K_{h}}+0.365 \tan \varphi+0.329 \frac{L}{B}
$$

\section{Results and discussion}

In this study, the overall performance of the developed models was assessed using the statistical analyses of the predicted and calculated kc values. The results of the statistical performance of the optimal ANN models with best geometries are shown in Table 3. As it can be seen, for ANN1, the $\mathrm{R}^{2}$ values are very close to one while MSE and MAE values are close to zero, indicating excellent agreement between the assessment results and forecasted results of kc. Also, it can be noticed that the predicted kc values from ANN2 and MR1 models are in good agreement with kc observed, as their $\mathrm{R}^{2}>0.8$ [17]. 
Table 3. Statistics and performance parameters of the optimal models

\begin{tabular}{|c|c|c|c|c|}
\hline Optimal model & Set & $\mathrm{R}^{2}$ & RMSE & MAE \\
\hline \multirow{2}{*}{$\begin{array}{c}\text { ANN1 } \\
(8-14-1)\end{array}$} & Training & 0.999 & 0.0412 & 0.0025 \\
\cline { 2 - 5 } & Validation & 0.987 & 0.0591 & 0.0048 \\
\cline { 2 - 5 } & Test & 0.993 & 0.0707 & 0.0084 \\
\hline \multirow{2}{*}{ MR1 } & All data & 0.817 & 0.0697 & 0.0548 \\
\hline \multirow{2}{*}{$\begin{array}{c}\text { ANN2 } \\
(4-4-1)\end{array}$} & Training & 0.836 & 0.0648 & 0.0364 \\
\cline { 2 - 5 } & Validation & 0.873 & 0.0656 & 0.0283 \\
\cline { 2 - 5 } & Test & 0.810 & 0.0728 & 0.0554 \\
\hline MR2 & All data & 0.650 & 0.0964 & 0.0736 \\
\hline
\end{tabular}

Figure 3 shows that the values forecast by the developed ANN models fit perfectly with the computed values. High performances of the training step, testing step, and validation step indicate that the learning process of the optimal predictive model is successful, hence, the R-value is over 0.899 for the whole response for both models. Obviously, it can be noted that the ANN1 model developed exhibits higher prediction performance than the ANN2 model based on the performance criteria, similarly for MR models. Also, the ANN models developed demonstrate a higher prediction performance than MR models, which demonstrates the effectiveness of the ANN approach.

a)
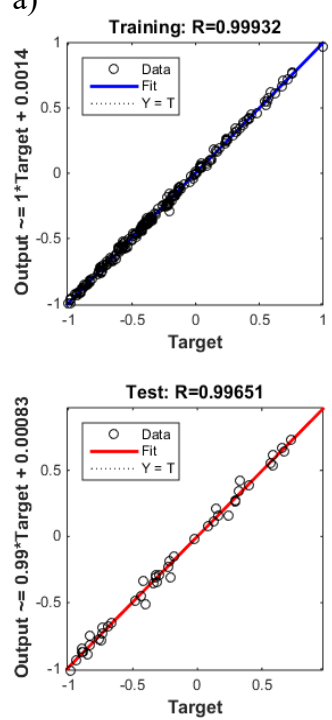
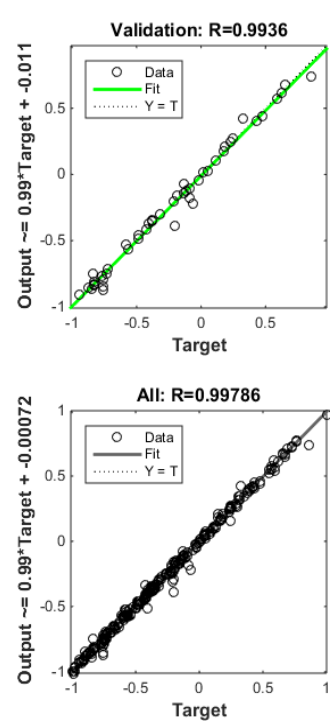

b)
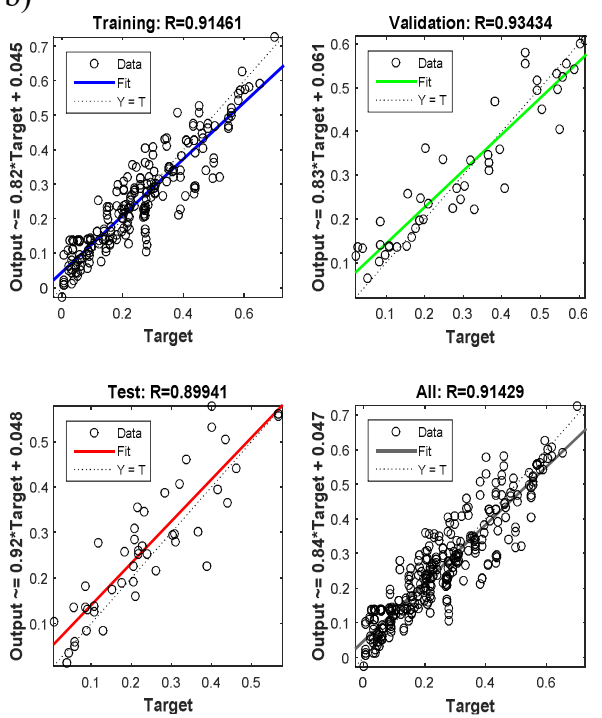

Fig. 3. R values of training, validation, test and all data for optimal models: a) FBNN1, b) FBNN2

The plots of network performance (MSE) at different epochs for both models (FBNN1 and FBNN2) are shown in Figure 4. According to these plots, the devel- 
oped models are processed because the MSE of the network starting at a high value and decreasing to a lower value. This figure also shows that the test set error and the validation set errors have similar characteristics and that there does not seem to have been a significant overfitting.

On the other hand, to look for a statistically significant difference between calculated and predicted kc values, a paired t-test was performed by using the GraphPad Software. The $p$ value was found as $(0.345,0.427)$ and $(0.651,0.473)$ for the ANN and MR models, respectively, indicating that no significant difference in kc values was observed between computed and forecasted values for all models $(\mathrm{p}>0.05)$.

a)

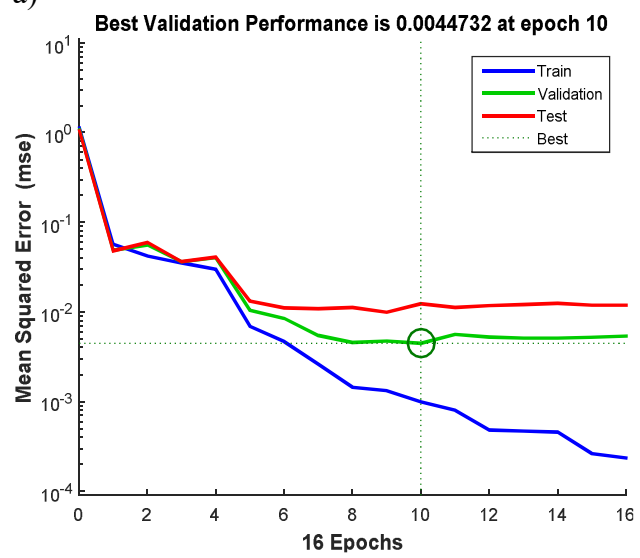

b)

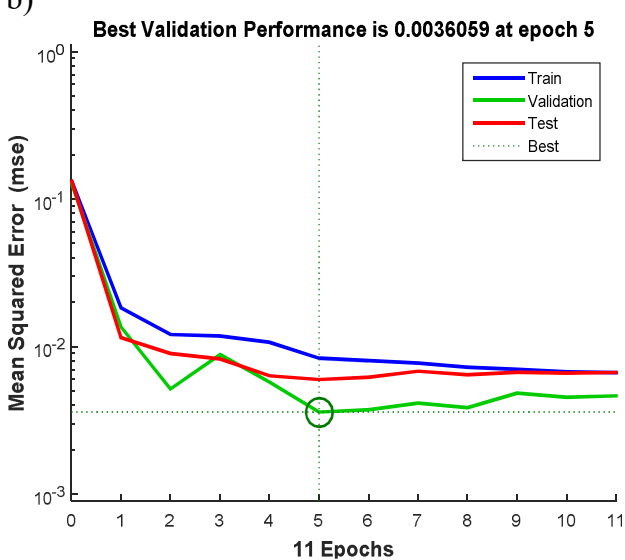

Fig. 4. Best validation performance: a) FBNN1, b) FBNN2

\subsection{Sensitivity analysis}

The relative importance of the various input issues can be assessed by examining the connection weights. Garson [18] proposed an equation that included partitioning the hidden-output connection weights of each hidden neuron into components associated with each input neuron:

$$
(R I)_{j}=\frac{\sum_{m=1}^{m=N h}\left(\left(\left|\boldsymbol{W}_{j m}^{i h}\right| / \sum_{k=1}^{N i}\left|\boldsymbol{W}_{k m}^{i h}\right|\right) \times\left|\boldsymbol{W}_{m n}^{h o}\right|\right)}{\sum_{k=1}^{N i}\left\{\sum_{m=1}^{N h}\left(\left|\boldsymbol{W}_{k m}^{i h}\right| / \sum_{k=1}^{N i}\left|\boldsymbol{W}_{k m}^{i h}\right|\right) \times\left|\boldsymbol{W}_{m n}^{h o}\right|\right\}}
$$

where $R I_{j}$ is the relative importance of the $j$-th input variable on the output variable, $w$ is connection weight, $N i$ and $N h$ are the numbers of input and hidden neurons respectively, the subscripts " $k$ ", " $m$ " and " $n$ " refer to input, hidden and output neurons respectively, and the superscripts "i", "h" and "o" refer to input, hidden and output layers respectively. 
Table 4 shows the weights of the input-hidden layer connections, the hiddenoutput layer connections, and biases for model (4-4-1). The weights and biases can be used for sensitivity analysis and framing an ANN model in equation form.

Table 4. Connection weights and biases of the optimal ANN2 model

\begin{tabular}{|c|c|c|c|c|c|c|c|}
\hline \multirow{3}{*}{ Neuron } & \multicolumn{4}{|c|}{$w 1$} & $w 2$ & \multicolumn{2}{c|}{ Biases } \\
\cline { 2 - 8 } & \multicolumn{4}{|c|}{ Input neurons } & Output & & \\
\cline { 2 - 8 } & $\gamma / \mathrm{H}_{\mathrm{c}}$ & $\mathrm{K}_{\mathrm{v}} / \mathrm{K}_{\mathrm{h}}$ & $\tan \varphi$ & $\mathrm{L} / \mathrm{B}$ & $\mathrm{kc}$ & $b_{h k}$ & $b_{0}$ \\
\hline 1 & 2.3123 & -1.6702 & 0.43082 & 0.39334 & -0.47731 & -2.4001 & -0.32977 \\
\hline 2 & -1.8787 & 0.25268 & -1.3399 & -0.60174 & -0.50553 & 1.716 & \\
\hline 3 & 1.0478 & 1.8986 & -2.7067 & -0.36643 & -2.7263 & 0.28588 & \\
\hline 4 & 4.2262 & -0.61591 & 0.67505 & 4.0793 & 3.1077 & -0.51371 & \\
\hline
\end{tabular}

The results of relative importance of inputs are shown in Table 5. The results indicate that the $\varphi, \mathrm{H}, \mathrm{K}_{\mathrm{v}}, \mathrm{K}_{\mathrm{h}}$, and $\mathrm{c}$ are the most important parameters affecting $\mathrm{kc}$. The results also show that the $\mathrm{B}, \mathrm{L}$ and $\gamma$ have less effect on $\mathrm{kc}$.

Table 5. Relative importance of different input variables

\begin{tabular}{|c|c|c|c|c|c|c|c|c|}
\hline Input variable & $\mathrm{B}$ & $\mathrm{L}$ & $\mathrm{H}$ & $\gamma$ & $\mathrm{c}$ & $\varphi$ & $\mathrm{K}_{\mathrm{h}}$ & $\mathrm{K}_{\mathrm{v}}$ \\
\hline Relative Importance & 3.188 & 4.395 & 17.435 & 6.110 & 9.360 & 29.398 & 14.603 & 15.510 \\
\hline
\end{tabular}

\subsection{Explicit formulation of ANN2 model}

The model equation for the output can be formulated based on the trained weights of the ANN model [19]. In this study, the basic mathematical equation relating the independent variables and the critical seismic coefficient value based on trained neural network can be written as:

$$
\mathrm{kc}=f\left\{b_{0}+\sum_{k=1}^{h}\left[w_{k} * f\left(b_{h k}+\sum_{i=1}^{m} w_{i k} X_{i}\right)\right]\right\}
$$

where $w_{i k}$ is the connection weight between $i$-th input variable and $k$-th neuron of hidden layer; $X_{i}$ is the input variable and $f$ is the sigmoid transfer function. $h$ is the number of neurons in the hidden layer.

So, such a model equation for critical seismic coefficient $(\mathrm{kc})$ was established using the values of the weights and biases shown in Table 4 as per the following expressions:

$$
\left\{\begin{array}{l}
A 1=2.3123\left(\frac{\gamma}{\mathrm{H}_{\mathrm{c}}}\right)+-1.6702\left(\frac{\mathrm{K}_{\mathrm{v}}}{\mathrm{K}_{\mathrm{h}}}\right)+0.43082(\tan \varphi)+0.39334\left(\frac{\mathrm{L}}{\mathrm{B}}\right)-2.4001 \\
A 2=-1.8787\left(\frac{\gamma}{\mathrm{H}_{\mathrm{c}}}\right)+0.25268\left(\frac{\mathrm{K}_{\mathrm{v}}}{\mathrm{K}_{\mathrm{h}}}\right)-1.3399(\tan \varphi)-0.60174\left(\frac{\mathrm{L}}{\mathrm{B}}\right)+1.716 \\
A 3=1.0478\left(\frac{\gamma}{\mathrm{H}_{\mathrm{c}}}\right)+1.8986\left(\frac{\mathrm{K}_{\mathrm{v}}}{\mathrm{K}_{\mathrm{h}}}\right)-2.7067(\tan \varphi)-0.36643\left(\frac{\mathrm{L}}{\mathrm{B}}\right)+0.28588 \\
A 4=4.2262\left(\frac{\gamma}{\mathrm{H}_{\mathrm{c}}}\right)-0.61591\left(\frac{\mathrm{K}_{\mathrm{v}}}{\mathrm{K}_{\mathrm{h}}}\right)+0.67505(\tan \varphi)+4.0793\left(\frac{\mathrm{L}}{\mathrm{B}}\right)-0.51371
\end{array}\right.
$$




$$
\left\{\begin{array}{l}
B_{1}=-0.47731\left(\frac{1}{1+\mathrm{e}^{-\mathrm{A} 1}}\right) \\
B_{2}=-0.50553\left(\frac{1}{1+\mathrm{e}^{-\mathrm{A} 2}}\right) \\
B_{3}=-2.7263\left(\frac{1}{1+\mathrm{e}^{-\mathrm{A} 3}}\right) \\
B_{4}=-2.7263\left(\frac{1}{1+\mathrm{e}^{-\mathrm{A} 4}}\right) \\
\mathrm{kc}=\frac{1}{1+e^{-(-0.32977+B 1+B 2+B 3+B 4)}}
\end{array}\right.
$$

\subsection{Comparison with other methods}

For this purpose, we have arbitrarily chosen three new cases with input values that are not similar to values adopted in the database. Table 6 shows the selected input variables for each of the three cases used. Table 7 shows the results obtained from FELA (OptumG2), FEM (GEO5) and the developed models (MR1, ANN1) for new cases.

Table 6. Selected input data for new cases

\begin{tabular}{|c|c|c|c|c|c|c|c|c|}
\hline \multirow{2}{*}{ Cases } & \multicolumn{70}{|c|}{ Input variable } \\
\cline { 2 - 9 } & $\mathrm{B}$ & $\mathrm{L}$ & $\mathrm{H}$ & $\mathrm{c}$ & $\varphi$ & $\gamma$ & $\mathrm{K}_{\mathrm{h}}$ & $\mathrm{K}_{\mathrm{v}}$ \\
\hline 1 & 98 & 30 & 20 & 5 & 25 & 17 & 0,1 & 0,1 \\
\hline 2 & 102 & 0 & 20 & 25 & 40 & 19 & 0,1 & 0,02 \\
\hline 3 & 142 & 40 & 20 & 10 & 20 & 15 & 0,001 & 0,0002 \\
\hline
\end{tabular}

Table 7. Comparison of results obtained from different methods

\begin{tabular}{|c|c|c|c|c|c|c|c|}
\hline Cases & $\begin{array}{c}\mathrm{kc} \\
(\text { OptumG2) }\end{array}$ & $\begin{array}{c}\mathrm{kc} \\
(\mathrm{GEO} 5 \mathrm{FEM})\end{array}$ & $\begin{array}{c}\text { Relative } \\
\text { error } \\
{[\%]}\end{array}$ & $\begin{array}{c}\mathrm{kc} \\
(\mathrm{ANN} 1)\end{array}$ & $\begin{array}{c}\text { Relative } \\
\text { error } \\
{[\%]}\end{array}$ & $\begin{array}{c}\mathrm{kc} \\
(\mathrm{MR} 1)\end{array}$ & $\begin{array}{c}\text { Relative } \\
\text { error } \\
(\%)\end{array}$ \\
\hline 1 & 0.0925 & 0.00 & 89.19 & 0.1026 & -10.92 & 0.0883 & 4.45 \\
\hline 2 & 0.355 & 0.35 & 0.17 & 0.3057 & 13.89 & 0.25678 & 27.66 \\
\hline 3 & 0.146 & 0.1 & 31.51 & 0.1731 & -18.56 & 0.21573 & -47.76 \\
\hline
\end{tabular}

\section{Conclusions}

In this study, the critical seismic coefficient of homogenous earth dams has been predicted by Artificial Neural Network models. The prediction of these critical 
seismic coefficients requires the use of OptumG2 FELA software with identified ranges of variables to build a representative database. For a specified set of independent variables, the (8-14-1) and (4-4-1) ANN models were found to be capable of estimating the kc accurately. The error estimated is very low which indicates that the approach is applicable accurately and rapidity as compared to other techniques (conventional and numeric methods). Moreover, the results of sensitivity analysis showed that angle of friction $(\varphi)$ is the most important parameter affecting kc with relative importance of $29.40 \%$.

\section{References}

[1] Newmark, N.M. (1965). Effects of earthquakes on dams and embankments. Geotechnique, 15(2), 139-160.

[2] Loukidis, D., Bandini, P., \& Salgado, R. (2003). Stability of seismically loaded slopes using limit analysis. Geotechnique, 53(5), 463-480.

[3] Tsai, C.C., \& Chien, Y.C. (2016). A simple procedure to directly estimate yield acceleration for seismic slope stability assessment. Japanese Geotechnical Society Special Publication, 2(25), 915-919.

[4] Leshchinsky, D., \& San, K.C. (1994). Pseudostatic seismic stability of slopes: Design charts. Journal of Geotechnical Engineering, 120(9), 1514-1532.

[5] Baker, R., Shukha, R., Operstein, V., \& Frydman, S. (2006). Stability charts for pseudo-static slope stability analysis. Soil Dynamics and Earthquake Engineering, 26(9), 813-823.

[6] Tan, D., \& Sarma, S.K. (2008). Finite element verification of an enhanced limit equilibrium method for slope analysis. Geotechnique, 58(6), 481-488.

[7] Zhou, H., Liu, H., Wang, L., \& Kong, G. (2018). Finite element limit analysis of ultimate lateral pressure of XCC pile in undrained clay. Computers and Geotechnics, 95, 240-246.

[8] Keawsawasvong, S., \& Ukritchon, B. (2017). Stability of unsupported conical excavations in non-homogeneous clays. Computers and Geotechnics, 81, 125-136.

[9] Das, S.K. (2013). Artificial neural networks in geotechnical engineering: modeling and application issues. In Metaheuristics in water, geotechnical and transport engineering (pp. 231-270).

[10] Krabbenhoft, K., Lyamin, A.V., \& Krabbenhoft, J. (2017). Optum Computational Engineering (Optum G2), Available on: <www. optumce. Com >.

[11] Khatri, V.N., Kumar, J., \& Akhtar, S. (2017). Bearing capacity of foundations with inclusion of dense sand layer over loose sand strata. International Journal of Geomechanics, 17(10), 06017018.

[12] Abrahart, R.J., See, L.M., \& Solomatine, D.P. (Eds.). (2008). Practical hydroinformatics: computational intelligence and technological developments in water applications (Vol. 68). Springer Science \& Business Media.

[13] Verma, A.K., Singh, T.N., Chauhan, N.K., \& Sarkar, K. (2016). A hybrid FEM-ANN approach for slope instability prediction. Journal of The Institution of Engineers (India): Series A, 97(3), 171-180.

[14] Choobbasti, A.J., Farrokhzad, F., \& Barari, A. (2009). Prediction of slope stability using artificial neural network (case study: Noabad, Mazandaran, Iran). Arabian Journal of Geosciences, 2(4), 311-319.

[15] Haykin, S. (1999). Adaptive filters. Signal Processing Magazine, 6(1). 
[16] Şahin, M., Kaya, Y., \& Uyar, M. (2013). Comparison of ANN and MLR models for estimating solar radiation in Turkey using NOAA/AVHRR data. Advances in Space Research, 51(5), 891-904.

[17] Erzin, Y., \& Turkoz, D. (2016). Use of neural networks for the prediction of the CBR value of some Aegean sands. Neural Computing and Applications, 27(5), 1415-1426.

[18] Garson, G.D. (1991). Interpreting neural-network connection weights. AI Expert, 6(4), 46-51.

[19] Das, S.K., \& Basudhar, P.K. (2006). Undrained lateral load capacity of piles in clay using artificial neural network. Computers and Geotechnics, 33(8), 454-459. 